07

\title{
Модификация стандартной производственной линии Al-BSF фотоэлектрических преобразователей до PERC с использованием PECVD
}

\author{
(C) И.A. Клиновицкая, ${ }^{1}$ C.B. Плотников, ${ }^{1}$ P.M.L. Lay ${ }^{2}$ \\ ${ }^{1}$ Восточно-Казахстанский технический университет им. Д. Серикбаева, \\ 070004 Усть-Каменогорск, Казахстан \\ ${ }^{2}$ ECM Technologies, 46 rue Jean Vaujany - Technisud, \\ F-38029 Grenoble, France \\ e-mail: iklinovitskaya@inbox.ru
}

Поступило в Редакцию 29 июля 2021 г.

В окончательной редакции 20 января 2022 г.

Принято к публикации 20 января 2022 г.

\begin{abstract}
Проведено комплексное исследование физических и электрических свойств фотоэлектрических преобразователей (ФЭП), изготовленных на основе казахстанского мультикристаллического кремния, так называемого солнечного качества. Применяемые методы исследования: 4-х точечный метод измерения сопротивления, метод микроволнового детектируемого фотопроводящего распада, метод индуцированного световым пучком тока, методы спектрометрического анализа коэффициентов отражения, пропускания и фотолюминесценции, сканирующая электронная микроскопия и метод измерения вольт-амперной характеристики. Изготовлены и проанализированы партии фотоэлектрических преобразователей с алюминиевым полем на тыльной поверхности (Al-BSF) и ФЭП с пассивированными эмиттерной и тыльной поверхностями (РЕRC) на основе казахстанского кремния. С целью повышения коэффициента полезного действия предложена модификация стандартной производственной линии Al-BSF до линии PERC с использованием метода ускоренного плазмой химического напыления из газовой фазы.
\end{abstract}

Ключевые слова: фотоэлектрические преобразователи, кремний, коэффициент полезного действия, Al-BSF, PERC, производство фотоэлектрических преобразователей, PECVD.

DOI: 10.21883/JTF.2022.04.52246.224-21

\section{Введение}

Предполагается, что фотоэлектрическое преобразование энергии будет играть важную роль на энергетическом рынке в будущем. По прогнозам Организации Объединенных Наций рост мирового населения составит с 7.7 миллиарда до 9.2 миллиарда человек к 2040 году, поэтому мировая потребность в энергии будет продолжать расти [1]. Так, мировое потребление энергии увеличится на 28\%. Солнечная энергия - самый важный и мощный источник энергии, доступный человечеству.

Фотоэлектрические преобразователи (ФЭП) на основе кристаллического кремния $(c-\mathrm{Si})$ являются наиболее распространенными ФЭП, на которые приходится около 90\% всей доли рынка фотоэлектрических систем. Эта технология обеспечивает наивысшую эффективность преобразования энергии среди всех коммерческих ФЭП и, как ожидается, продолжит играть главную роль в будущем на рынке фотоэлектрических систем [2].

В рамках перехода к ,зеленой“ экономике в 2010 году Казахстан приступил к реализации проекта по производству фотоэлектрических модулей на основе Сарыкольского месторождения кварца [3,4]. Сырьевой материал (кремний) производится по карботермической технологии на предприятии ТОО «Металлургический комбинат «KazSilicon»» в городе Уштобе. Выпуск ФЭП и сборка модулей производятся на заводах ТОО «Kazakhstan Solar Silicon» и ТОО «Astana Solar», в городах УстьКаменогорск и Нур-Султан соответственно.

Предметом настоящего исследования является производство ФЭП. Цель исследования заключается в изучении свойств и возможных стратегий модификации производственной линии для достижения высокоэффективных ФЭП с передовой архитектурой. Исследование свойств позволяет выявить причины снижения коэффициента полезного действия (КПД) ФЭП и определить способы его увеличения.

На протяжении последних десятилетий 90\% мирового производства ФЭП приходилось на технологию Al-BSF. Данная технология считается стандартной и обеспечивает стабильную эффективность наряду с надежным технологическим процессом [5].

Технология производства PERC ФЭП является обновленной технологией стандартной Al-BSF-технологии [6]. Основными преимуществами PERC перед Al-BSF являются уменьшенная рекомбинация и улучшенная отражательная способность за счет пассивации тыльной стороны преобразователя. Благодаря данной пассивации свет, достигающий тыльной стороны без генерации свободных носителей заряда, отражается назад в ФЭП, где имеет возможность создать электрический ток, генерируя больше свободных электронов [7,8]. 


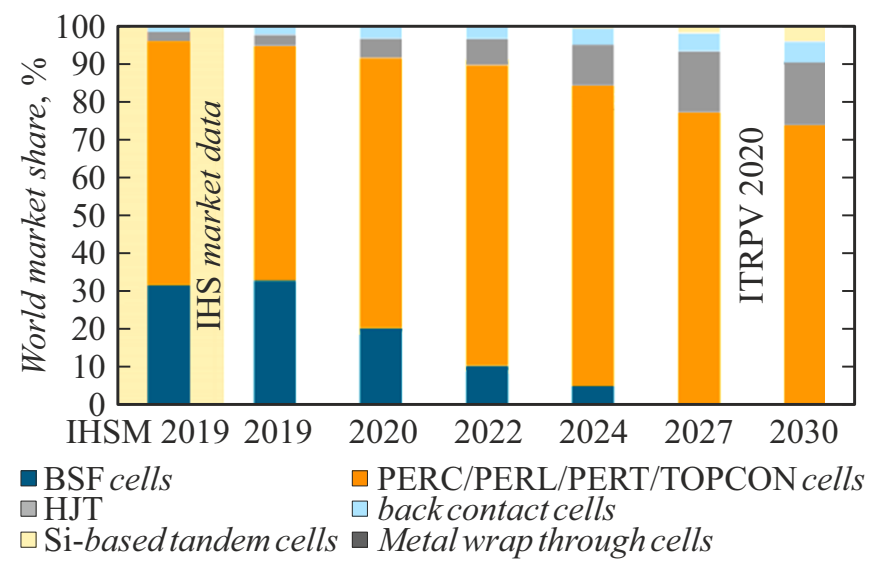

Рис. 1. Доля различных технологий на мировом рынке и прогнозы развития [2].

Конструкция PERC быстро завоевывает долю рынка в фотоэлектрической отрасли. Основной причиной перехода на PERC является повышенная эффективность по сравнению с Al-BSF. По данным исследований [2] средний КПД Al-BSF ФЭП составляет 18\%, тогда как ФЭП на основе $\mathrm{c}-\mathrm{Si}$, произведенные по PERC-технологии, обеспечивают эффективность в диапазоне 21-24\%. Также важно отметить, что технология PERC совместима с существующим оборудованием для производства ФЭП, и переход на новую технологию является несложным. Согласно [2], доля PERC ФЭП на мировом рынке в фотоэлектрической отрасли составила чуть больше $30 \%$ в 2019 году и достигнет 50\% мировой фотоэлектрической индустрии в 2020-х годах. Прогнозы производства ФЭП различного типа приведены на рис. 1 .

Для исследования возможности перехода на новую технологию были изготовлены партии Al-BSF и PERC ФЭП. Материалом для исследования были выбраны кремниевые пластины (КП), изготовленные из казахстанского мультикристаллического кремния качества SoG-Si.

\section{1. Стандартная Al-BSF-структура и методы изготовления}

Технологический процесс производства стандартных ФЭП на основе Al-BSF-технологии (Al-BSF ФЭП) состоит из следующих основных процессов [9]:

- текстуризация;

- диффузия фосфора, создание $p-n$-перехода;

- удаление фосфорсиликатного стекла (ФСС) и травление паразитного эмиттера;

- нанесение антиотражающего покрытия методом ускоренного плазмой химического напыления из газовой фазы (PECVD);

- создание токособирающих шин и контактной сетки (металлизация) методом трафаретной печати;
- сушка тыльного алюминиевого сплошного поля и вжигание контактов;

- измерение вольт-амперной характеристики (BAX) готовых ФЭП.

На рис. 2 представлено схематическое изображение структуры стандартного Al-BSF ФЭП.

Для изготовления образцов Al-BSF ФЭП использовались КП толщиной 180-200 $\mu \mathrm{m}$, удельным сопротивлением $\sim 2 \Omega \cdot \mathrm{cm}$ и размером $156 \times 156 \mathrm{~mm}$. На всех пластинах было проведено кислотное анизотропное текстурирование, которое состояло из следующих этапов: текстурирование в растворе фторводородной кислоты (HF) с концентрацией 50\% и азотной кислоты $\left(\mathrm{HNO}_{3}\right)$ с концентрацией 65\% при температуре $10^{\circ} \mathrm{C}$ в течение $152 \mathrm{~s}$; травление пористого слоя в растворе щелочи $\mathrm{KOH} \mathrm{с} \mathrm{концентрацией} 45 \%$ при температуре $20^{\circ} \mathrm{C}$ в течение $22 \mathrm{~s}$; восстановление, травление металлов в растворе кислоты HF с концентрацией 50\% и кислоты $\mathrm{HCl}$ с концентрацией $37 \%$ при температуре $22^{\circ} \mathrm{C}$ в течение $50 \mathrm{~s}$. После каждого этапа проводилась двухстадийная промывка в деионизированной воде. Текстурирование поверхности пластин выполняется для существенного снижения коэффициента отражения и скорости поверхностной рекомбинации. Травление металлов в растворе плавиковой и соляной кислот проводится для того, чтобы поверхность была свободной от загрязнений перед следующим этапом - диффузией фосфора. Наличие большого количества металлических примесей и щелочных остатков может привести к большому числу дефектов в $p-n$-переходе. Изображение поверхности КП до и после процесса текстуризации, полученное с помощью сканирующего электронного микроскопа (СЭМ) JSM-6390LV (Jeol, Япония), приведено на рис. 3.

После процесса текстуризации на обеих сторонах поверхностей КП образовались лунки вне зависимости от ориентации кристалитов. Появление такой структуры, как лунки, связано с тем, что пластины из мультикристаллического кремния не имеют единой кристалографической ориентации, и тектстурирование произведено в изотропном кислотном растворе.

На следующем этапе был сформирован эмиттер ( $p-n$ переход) методом диффузии фосфора. Легирование проводилось при давлении несколько ниже атмосферного при температуре $830-860^{\circ} \mathrm{C}$. В ходе эксперимента для

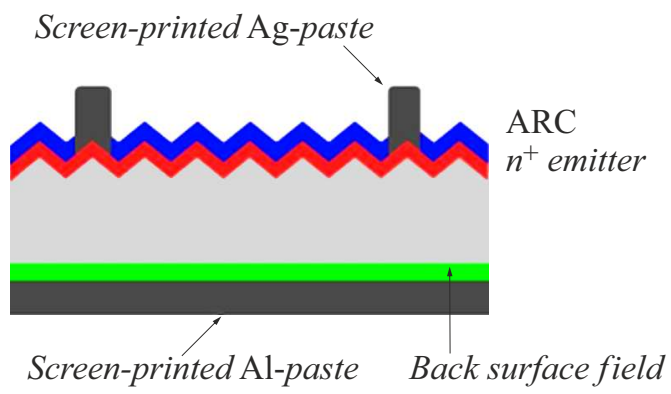

Рис. 2. Схематическое изображение структуры стандартного Al-BSF ФЭП. 

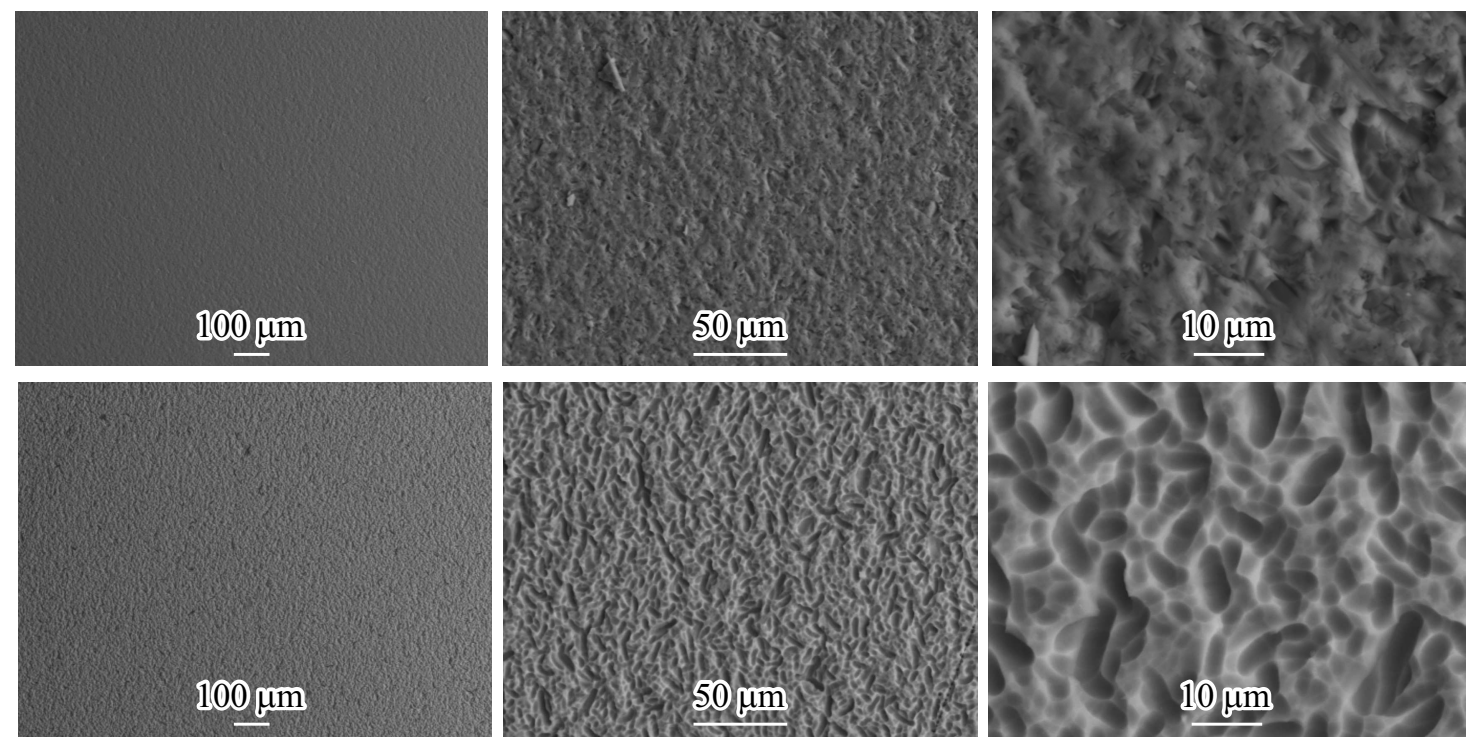

$a$

Рис. 3. СЭМ изображение поверхности КП с различным увеличением до $(a)$ и после $(b)$ текстурирования.

создания эмиттера использовалась дуффузионная печь Semco Engineering (Lydop). Источником фосфора являлся оксихлорид фосфора $\left(\mathrm{POCl}_{3}\right)$, который подавался в печь вместе с азотом. Внутри печи в присутствии кислорода происходит реакция разложения:

$$
2 \mathrm{POCl}_{3}+\mathrm{O}_{2}=2 \mathrm{P}+2 \mathrm{O}_{2}+3 \mathrm{Cl}_{2} \text {. }
$$

Затем происходят следующие реакции:

$$
\begin{gathered}
4 \mathrm{P}+5 \mathrm{O}_{2}=2 \mathrm{P}_{2} \mathrm{O}_{5}, \\
2 \mathrm{P}_{2} \mathrm{O}_{5}+5 \mathrm{Si}=5 \mathrm{SiO}_{2}+4 \mathrm{P} .
\end{gathered}
$$

В целом процесс диффузии делится на три этапа [4]:

- образование на поверхности пластины ФСС;

— диффузия фосфора из ФСС в приповерхностный слой;

- диффузия фосфора из приповерхностного слоя в объем.

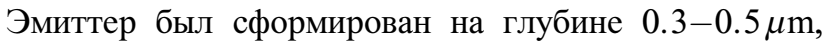
поверхностное сопротивление $65 \pm 5 \Omega / \mathrm{sq}$, среднее время жизни неосновных носителей заряда составило $>10 \mu \mathrm{s}$.

Как известно [10], во время диффузии образуется ФСС и $n$-слой не только на лицевой стороне пластины, но и на ее торцах и на тыльной поверхности. При этом имеет место электрическое замыкание между лицевым и тыльным токосъемными контактами. Поэтому для удаления ФСС и травления паразитного эмиттера кремниевые пластины были помещены в раствор плавиковой и азотной кислот $\left(\mathrm{HF} / \mathrm{HNO}_{3}\right)$ для травления $n$ слоя, таким образом, чтобы передняя поверхность не контактировала с раствором. После травления пластины поместили в раствор КОН, который разбрызгивается на лицевую поверхность и смачивает тыльную поверхность. На этом этапе удаляется слой пористого кремния.
На следующем этапе на поверхность пластин было нанесено антиотражающее покрытие (АОП) методом PECVD. Нитрид кремния $\left(\mathrm{SiN}_{y}\right)$ стал самым надежным пассивирующим материалом для лицевой стороны ФЭП, ввиду его превосходных антиотражающих свойств, а также способности обеспечивать поляризующую пассивацию наряду с умеренным уменьшением поверхностных состояний. Пассивация лицевой поверхности ФЭП пленкой $\mathrm{SiN}_{y}$, нанесенной методом PECVD, позволила достичь рекордно низкой эффективной скорости поверхностной рекомбинации [11]. Процесс проводится в присутствии силана $\mathrm{SiH}_{4}$ и аммиака $\mathrm{NH}_{3}$ за счет создания радиочастотного электрического поля между противоположными электродами, что вызывает газовый разряд. При этом внутри реактора происходят реакции, описываемые следующими уравнениями:

$$
\begin{aligned}
& 2 \mathrm{SiH}_{4}+\mathrm{N}_{2}=2 \mathrm{SiNH}+3 \mathrm{H}_{2}, \\
& \mathrm{SiH}_{4}+\mathrm{NH}_{3}=\mathrm{SiNH}+3 \mathrm{H}_{2} .
\end{aligned}
$$

C помощью процесса PECVD одновременно с нанесением АОП проводилось пассивирование и гидрирование объемного материала пластины для улучшения КПД. В результате на лицевой поверхности пластины была „выращена“ тончайшая пленка нитрида кремния, которая обладает требуемыми свойствами. Ее показатель преломления составил $n=2-2.15$ при толщине пленки около $70 \mathrm{~nm}$.

Для нанесения шин и контактной сетки использовали метод трафаретной печати, который позволяет наносить достаточно узкие по размерам контакты (стандартная ширина контакта порядка 75-100 $\mu \mathrm{m})$, для того чтобы уменьшить затенение поверхности в готовом ФЭП. Процесс заключается в использовании специальных экранов определенного рисунка, через которые продавливается 
проводниковая паста. Для шин и контактной сетки на лицевой поверхности фотоэлемента применялась серебросодержащая проводниковая паста с удельным сопротивлением менее $2 \mathrm{~m} \Omega / \mathrm{sq}$ и вязкостью $16-23 \mathrm{~Pa} \cdot \mathrm{s}$, a для токосъемных шин на тыльной стороне - серебряная паста с сопротивлением $5 \mathrm{~m} \Omega$ /sq и вязкостью $89 \mathrm{~Pa} \cdot \mathrm{s}$. Для нанесения BSF использовалась алюминиевая паста с сопротивлением $0.05 \Omega / \mathrm{sq}$ и вязкостью 50-70 Pa $\cdot \mathrm{s}$.

Сушка контактных шин и сетки производилась при температуре $200-250^{\circ} \mathrm{C}$ после каждого нанесения пасты для выпаривания растворителя. Вжигание контактов было проведено в ленточной ИК-печи Despatch CDF Series (США). Сначала был произведен предварительный нагрев, затем при температуре $500-600^{\circ} \mathrm{C}$ спаивание частиц порошка металла. После этого температуру повысили до $710^{\circ} \mathrm{C}$ для создания заднего контакта, и наконец, при максимальной температуре в $860^{\circ} \mathrm{C}$ достигли образование фронтального контакта.

\section{PERC-структура и методы изготовления}

Технология PERC постепенно становится наиболее рентабельным выбором для массового производства ФЭП и позволяет превзойти $20 \%$-й уровень эффективности ФЭП на основе $c$-Si [12].

Следует отметить, что ФЭП на основе PERCтехнологии (PERC ФЭП) являются естественной прогрессией Al-BSF ФЭП. Схематическое изображение структуры PERC ФЭП представлено на рис. 4.

Электрические и оптические потери, свойственные для Al-BSF ФЭП и приводящие к снижению КПД стандартного ФЭП, могут быть исключены путем нанесения на тыльную сторону ФЭП дополнительного диэлектрического пассивирующего слоя (DPL). В настоящей работе для нанесения пленок $\mathrm{Al}_{2} \mathrm{O}_{3}$ и $\mathrm{SiN}_{y}$ использовался метод ускоренного плазмой химического напыления из газовой фазы. Данный метод заключается в разложении реакционных газов на радикалы при помощи газоразрядной плазмы, после чего происходит осаждение радикалов на поверхность кремниевой пластины.

Для изготовления образцов PERC ФЭП использовались кремниевые пластины толщиной 180-200 $\mu \mathrm{m}$, с удельным сопротивлением $\sim 1-2 \Omega \cdot \mathrm{cm}$ и размером $156 \times 156 \mathrm{~mm}$. Выбранная последовательность технологических операций следующая:

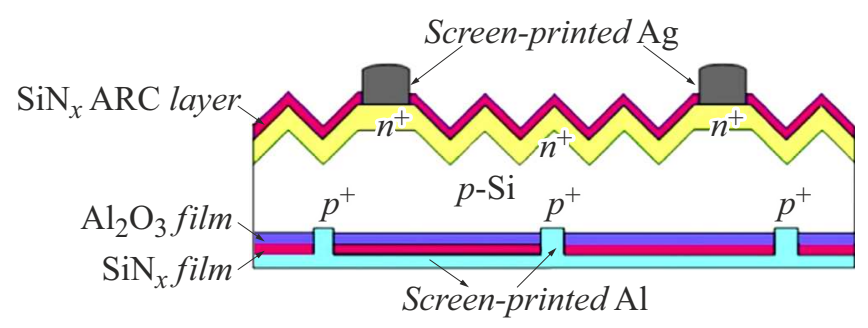

Pис. 4. Схематическое изображение структуры PERC ФЭП.
- текстуризация;

- диффузия фосфора, создание $p-n$-перехода;

- удаление ФСС, травление паразитного эмиттера и полировка тыльной стороны;

- нанесение покрытия $\mathrm{AlO}_{x} / \mathrm{SiO}_{x} \mathrm{~N}_{y} / \mathrm{SiN}_{1} / \mathrm{SiN}_{2}$ на тыльную сторону пластины методом PECVD;

- нанесение двойного антиотражающего покрытия (D-ARC) $\mathrm{SiO}_{x} / \mathrm{SiN}_{x}$ на лицевую сторону пластины методом PECVD;

- лазерная абляция (создание схемы заднего контакта);

- металлизация методом трафаретной печати;

- вжигание контактов методом быстрой термической обработки;

- измерение ВАХ готовых ФЭП.

Как было отмечено выше, производство PERC ФЭП предполагает нанесение пассивирующего слоя на тыльную сторону ФЭП, который затем „открывают“ с помощью лазера для формирования тыльного контакта. Эти дополнительные этапы являются основными и наиболее важными для перехода от технологии Al-BSF к PERC (рис. 5). Кроме того, необходимо оптимизировать этап удаления паразитного эмиттера и фосфор-силикатного стекла для полировки (травления) тыльной поверхности. Таким образом, за счет травления пирамидальной структуры с тыльной стороны удаляется одна из текстурированных поверхностей.

Эмиттер был сформирован на глубине $0.4 \mu \mathrm{m}$ методом диффузии фосфора, который использовался для создания $p-n$-перехода в Al-BSF ФЭП. Поверхностное сопротивление составило $90 \pm 2 \Omega / \mathrm{sq}$, среднее время жизни неосновных носителей заряда более $10 \mu \mathrm{s}$. Удаление ФСС, травление паразитного эмиттера и полировку тыльной стороны выполняли влажным химическим способом с использованием раствора $\mathrm{HNO}_{3}-\mathrm{HF}-\mathrm{H}_{2} \mathrm{SO}_{4}$. Время полировки составляло порядка $150 \mathrm{~s}$, толщина стравленного слоя составила $1 \mu \mathrm{m}$. Полированная задняя поверхность улучшает поглощательную способность света КП и обеспечивает эффективное пассивирование поверхности на дальнейших этапах.

Для нанесения тыльного пассивирующего слоя (рис. 6) использовали установку Twin PECVD For PERC Technology. При этом общий принцип осаждения методом PECVD, а также мощность радиочастоты, используемой для диссоциации прекурсоров при низком давлении и приводящей к осаждению пленки на поверхности пластины в реакторе, остаются прежними. Для нанесения слоя $\mathrm{AlO}_{x}$ использовали газовую смесь, состоящую из ТМА (trimethylaluminium) и $\mathrm{N}_{2} \mathrm{O}$, для слоев $\mathrm{SiO}_{x} \mathrm{~N}_{y} / \mathrm{SiN}_{1} / \mathrm{SiN}_{2}$ - технологические газы $\mathrm{SiH}_{4}$ и $\mathrm{NH}_{3}$. Следует отметить, что весь слой DPL был нанесен в один процесс.

Оксид алюминия $\left(\mathrm{AlO}_{x}\right)$, обладающий высоким уровнем пассивации, является предпочтительным пассивирующим материалом для тыльной стороны ФЭП. Свойства упомянутого оксида принципиально отличаются от свойств других диэлектрических материалов, часто 

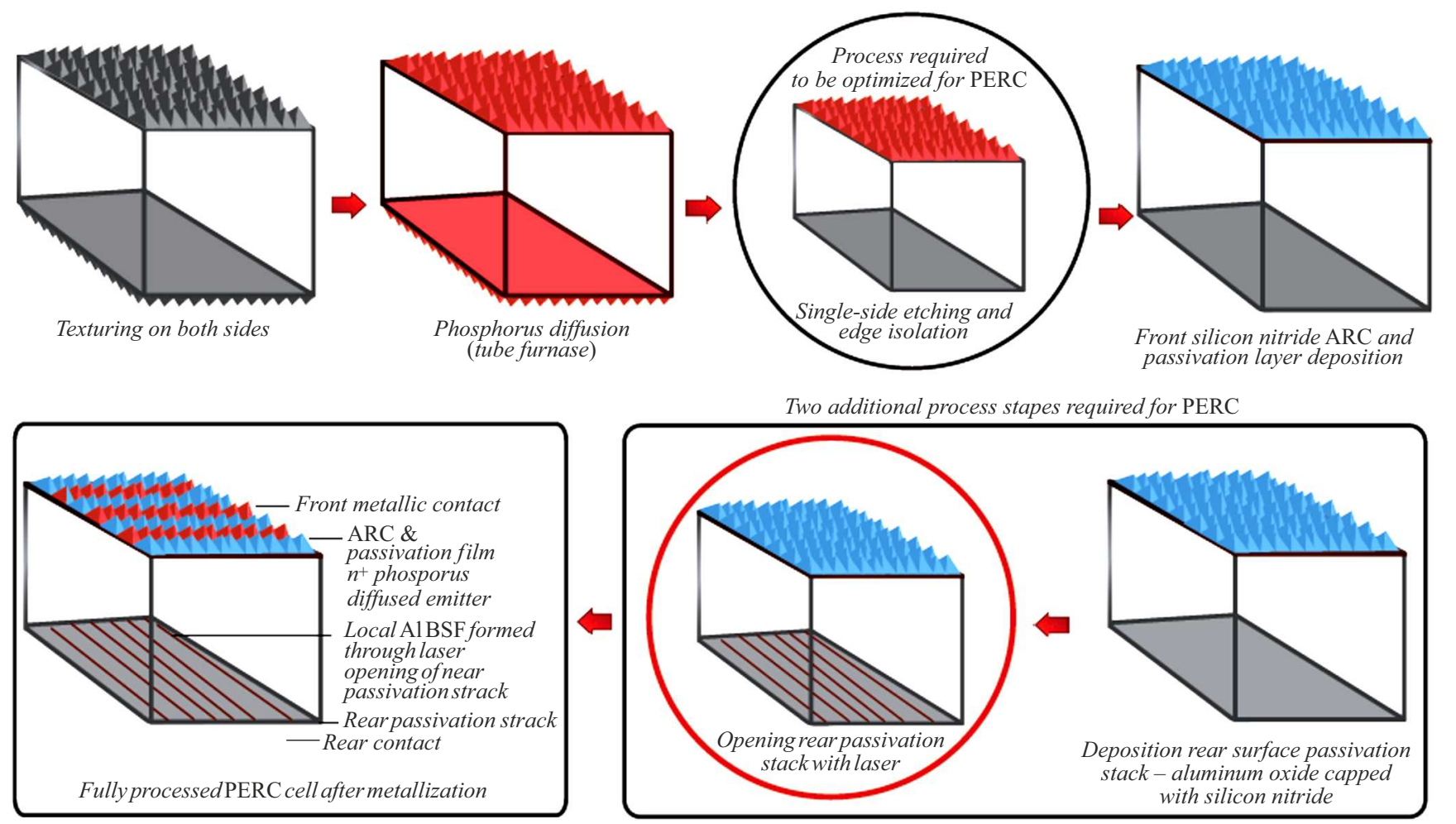

Рис. 5. Схема технологического процесса производства PERC ФЭП в сравнении со стандартным процессом производства Al-BSF ФЭП [13].

используемых для пассивации. Оксид алюминия имеет высокую плотность фиксированного отрицательного заряда $\left(10^{13} \mathrm{~cm}^{-1}\right)$, в то время как другие применяемые материалы обычно имеют положительный заряд [14]. Высокая плотность фиксированного отрицательного заряда находится на границе раздела $\mathrm{AlO}_{x} / \mathrm{Si}$ и обеспечивает высокую поляризующую пассивацию за счет экранирования электронов от границы раздела. Также данный оксид обладает хорошими свойствами химической пассивации, выступающий в качестве резервуара водорода, подает водород для насыщения оборванных связей на поверхности пластины во время этапов термической обработки. Что касается оптических свойств, пленки $\mathrm{AlO}_{x}$ с шириной запрещенной зоны $6.4 \mathrm{eV}$ прозрачны для той части солнечного света, которая имеет отношение к применению в фотовольтаике [15]. Единственным недостатком является довольно низкий показатель преломления, равный 1.65 , что делает оксид алюминия менее пригодным для использования в качестве однослойной антиотражающей пленки на стороне эмиттера; тем не менее диэлектрик очень хорошо выполняет работу обратного отражателя.

В работе [16] показана зависимость эффективного времени жизни $\tau_{\text {eff }}$ от толщины слоя $\mathrm{AlO}_{x}$ и определена оптимальная толщина в $10-15 \mathrm{~nm}$. На установке Twin PECVD возможно регулировать толщину слоя, увеличивая или уменьшая время осаждения. Для проведения данного исследования были выбраны следующие толщи-

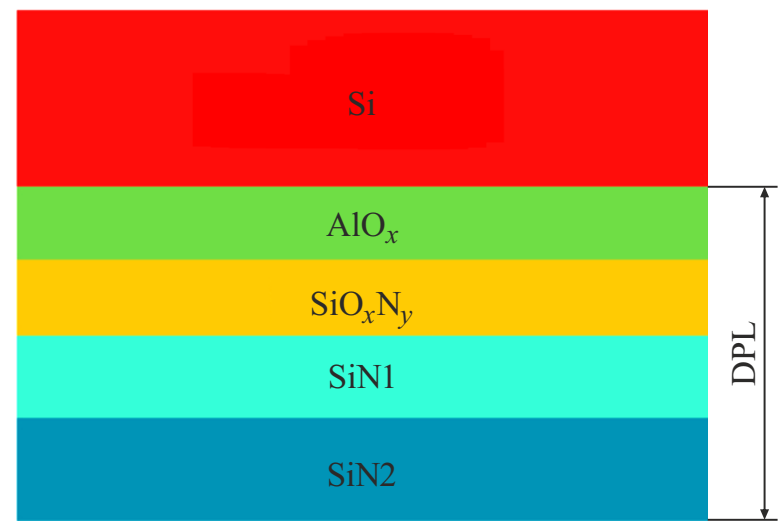

Рис. 6. Схема тыльного пассивирующего слоя.

ны слоев: $\mathrm{AlO}_{x}-10 \mathrm{~nm}, \mathrm{SiO}_{x} \mathrm{~N}_{y}-30 \mathrm{~nm}, \mathrm{SiN}_{1}-$ $50 \mathrm{~nm}, \mathrm{SiN}_{2}-100 \mathrm{~nm}$. Время процесса осаждения составило $45 \mathrm{~min}$, температура $-200-450^{\circ} \mathrm{C}$.

Для промышленного производства PERC ФЭП наиболее важной функцией слоя $\mathrm{SiN}_{y}$ является максимальная защита $\mathrm{AlO}_{x}$ от проникновения алюминиевый пасты, наносимой методом трафаретной печати [17]. Кроме того, PECVD-процесс осаждения пленки $\mathrm{SiN}_{y}$ участвует в активации слоя $\mathrm{AlO}_{x}$. Пленка $\mathrm{SiN}_{y}$ позволяет увеличить стабильность обжига пленки $\mathrm{AlO}_{x}$ и обеспечивает водородную пассивацию границы $\mathrm{Si} / \mathrm{AlO}_{x}$ и основного 
слоя кремния, что улучшает напряжение холостого хода и в некоторой степени производительность тока в готовом ФЭП.

Самым простым способом для „открытия“ тыльного пассивирующего слоя является использование лазерной технологии. На сегодняшний день на рынке фотовольтаической индустрии имеется большое количество лазерных решений, предлагаемых такими компаниями, как InnoLas Solutions, Rofin, 3D-Micromac, Schmid или Manz. „Открытие“ DPL-слоя в настоящей работе было проведено методом лазерной абляции.

Создание контактной сетки и шин было проведено методом трафаретной печати, как и для первой группы Al-BSF ФЭП. Однако для PERC-технологии требуются специальные метализационные пасты. Самым критичным продуктом для процесса метализации является паста для формирования задней поверхности BSF. Выбранная паста не должна реагировать со слоем DPL, но в то же время должна контактировать с областями, „открытыми“ с помощью лазера для формирования локального BSF. Также требуется химически инертная серебросодержащая паста для тыльных шин. Такая паста обладает двумя свойствами: она не должна проходить через DPL-слой и должна обладать хорошим уровнем адгезии и способностью к пайке.

Для измерения электрических параметров (BAX тока короткого замыкания $I_{\mathrm{sc}}$, напряжения холостого хода $U_{\text {oc, }}$ фактора заполнения $F F$, максимальной мощности $P_{\text {mpp }}$, эффективности, а также шунтирующего сопротивления $\left.R_{\mathrm{sh}}\right)$ в настоящей работе использовался импульсный тестер с ксеноновой лампой. Калиброванные лампы-вспышки солнечного симулятора освещают ФЭП, в то время как электронный регулятор нагрузки перемещает ячейку из условий полученной максимальной силы тока (тока короткого замыкания) в условия полученного максимального напряжения (напряжения холостого хода). Системный компьютер Berger собирает данные и вычисляет параметры ФЭП. Программное обеспечение позволяет управлять процессом снятия электрических характеристик с ФЭП.

\section{3. Исследование и анализ свойств Al-BSF ФЭП и PERC ФЭП}

В Национальном институте солнечной энергетики Франции INES было проведено исследование свойств и параметров КП и ФЭП. На первом этапе исследования были произведены замеры электрофизического параметра полупроводника - удельного сопротивления КП. Следует отметить, что исследованные КП использовались для изготовления партий PERC ФЭП и AlBSF ФЭП. Для этой цели удобнее всего использовать 4-х зондовый метод измерения, не требующий создания омического контакта к исследуемому образцу, что позволяет не разрушать материал и не изменять его свойства

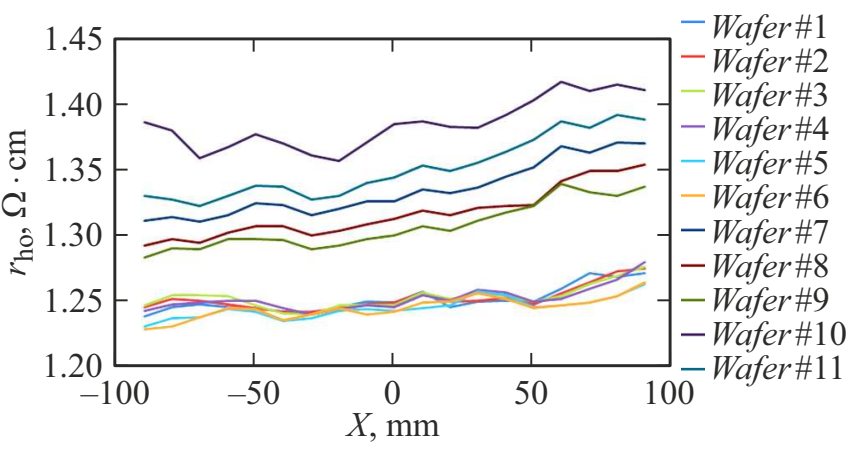

Рис. 7. Удельное сопротивление КП до обработки.

в процессе измерения. Поэтому для исследования удельного сопротивления использовался прибор измерения сопротивления 4-х точечным методом CMT SR2000N. Результаты измерений представлены на рис. 7.

Электрически активные и неактивные примеси оказывают сильное влияние на электрофизические характеристики кремния и параметры ФЭП. Они приводят к изменению времени жизни, коэффициентов поглощения, увеличению скорости поверхностной и объемной рекомбинации, изменению скорости диффузии элементов при легировании. Наличие примесей изменяет удельное сопротивление кремния и областей готового ФЭП. Как показано на рис. 7, удельное сопротивление исследуемых КП находится в диапазоне $r_{\mathrm{ho}}=1.228-1.417(\Omega \cdot \mathrm{cm})$. Равномерность распределения среднего значения $r_{\mathrm{ho}}$ по выборке КП составляет 5.46\%.

Также были получены фотолюминисцентные изображения (PL-изображения) КП до обработки (рис. 8) на измерительной системе Luminescence ImaGing System Model LIS-R1 и проведен их анализ. Как известно [18], PL-изображения показывают различные дефекты пластины, связанные с ее расположением в блоке (центральные блоки с низкой плотностью дислокаций, блоки с высокой плотностью дислокаций, блоки с примесями в нижней части, боковые блоки). В свою очередь, данные дефекты непосредственно снижают эффективность готовых ФЭП $[19,20]$. Дислокации негативно влияют как на ток короткого замыкания $I_{\mathrm{sc}}$, так и на напряжение холостого хода $U_{\text {oc. }}$ Специфическое влияние дислокаций и других дефектов на производительность готовых ФЭП напрямую зависят от процесса производства ФЭП, в частности, от способности данного процесса удалять или пассивировать дефекты посредством геттерирования и гидрирования. На основании исследования исходного материала был сделан вывод о необходимости дополнительной пассивации тыльной поверхности слоем DPL.

Темные зоны, присутствующие на PL-изображениях КП (рис. 8), являются местами скопления неизлучающих центров рекомбинации, что приводит к низкому значению времени жизни неосновных носителей. Увеличение количества дефектов приводит к уменьшению зна- 

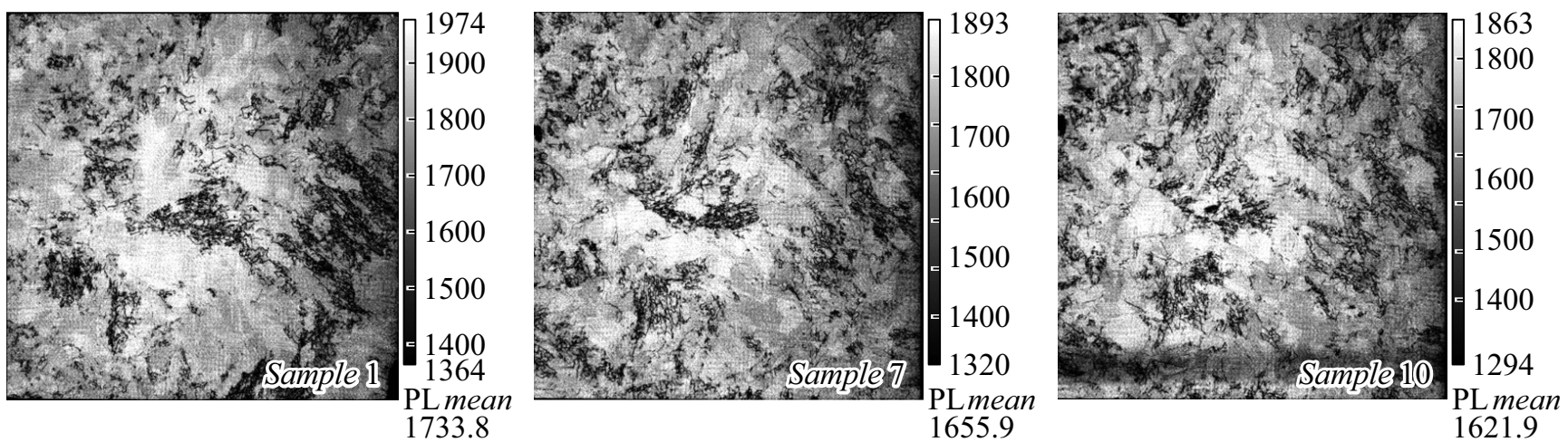

Рис. 8. PL-изображения КП до обработки (образцы 1,7,10), полученные на измерительной системе Luminescence ImaGing System - Model LIS-R1.

Значения электрических параметров, произведенных ФЭП

\begin{tabular}{c|c|c|c|c|c|c}
\hline $\begin{array}{c}\text { Тип } \\
\text { ФЭП }\end{array}$ & $\begin{array}{c}\text { Количество } \\
\text { ФЭП, штук }\end{array}$ & $\begin{array}{c}V_{\text {oc }}, \\
\mathrm{mV}\end{array}$ & $\begin{array}{c}I_{\mathrm{sc}}, \\
\mathrm{A}\end{array}$ & $\begin{array}{c}F F, \\
\%\end{array}$ & $\begin{array}{c}R_{\text {sh }}, \\
\Omega\end{array}$ & $\begin{array}{c}\text { Эффектив- } \\
\text { ность, \% }\end{array}$ \\
\hline Al-BSF & 400 & 610.3 & 8.5 & 76.80 & 102.3 & 15.83 \\
\hline PERC & 400 & 650 & 9.42 & 79.30 & 276.1 & 19.89
\end{tabular}

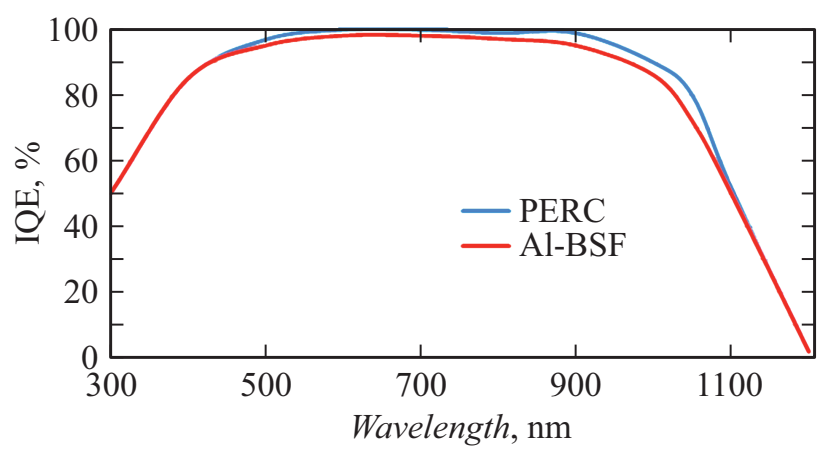

Рис. 9. Квантовая эффективность PЕRС и Al-BSF ФЭП.

чения напряжения холостого хода $U_{\text {ос }}$, что отрицательно влияет на производительность ФЭП.

Электрические параметры партий ФЭП, изготовленных по стандартной Al-BSF-технологии и обновленной PERC-технологии с использованием PECVD, приведены в таблице.

Как показано в таблице, произведенные PERC ФЭП имеют эффективность около $20 \%$, в среднем на $4 \%$ выше, чем Al-BSF ФЭП. Максимальное значение КПД среди изготовленных PERC ФЭП составило 21.01\%. Также следует отметить, что отличные пассивирующие свойства слоя $\mathrm{AlO}_{x} / \mathrm{SiO}_{x} \mathrm{~N}_{y} / \mathrm{SiN}_{1} / \mathrm{SiN}_{2}$ демонстрируются высоким значением напряжения холостого хода в $650 \mathrm{mV}$. Улучшенная пассивация тыльной стороны уменьшает количество рекомбинированных фотогенерируемых носителей заряда, что также привело к увеличению значения тока короткого замыкания.
Измерение квантовой эффективности (IQE) проводилось при помощи установки Semilab методом индуцированного световым пучком тока (LBIC). IQE это отношение количества собранных носителей заряда фотоэлементом к количеству фотонов заданной энергии, которые попадают на поверхность ФЭП и поглощаются. Результаты измерений изображены на рис. 9. Результаты исследования показали, что основное поглощение фотонов происходит в видимой и красной областях спектра.

Также на рис. 9 видно, что для PERC ФЭП сбор носителей в области 900-1000 nm выше, чем для Al-BSF ФЭП. Полученные результаты согласуются с литературными данными [16,21], поскольку было обнаружено, что нанесение слоя $\mathrm{Al}_{2} \mathrm{O}_{3}$ улучшает оптическую отражательную способность на тыльной стороне ФЭП и тем самым увеличивает поглощение за счет усиленного улавливания света, особенно в области ИК-света $(700-1000 \mathrm{~nm})$.

\section{Заключение}

В результате проведенного исследования были получены опытные образцы PERC ФЭП и Al-BSF ФЭП. Предложена схема тыльного пассивирующего слоя, наносимого методом PECVD. Определены оптимальные толщины слоев: $\mathrm{AlO}_{x}-10 \mathrm{~nm}, \mathrm{SiO}_{x} \mathrm{~N}_{y}-30 \mathrm{~nm}, \mathrm{SiN}_{1}-$ $50 \mathrm{~nm}, \mathrm{SiN}_{2}-100 \mathrm{~nm}$. Проведено исследование свойств полученных фотопреобразователей и достигнуто максимальное значение КПД, которое составило 21.01\% для PERC ФЭП. Таким образом, увеличение эффективности ФЭП при переходе на PERC можно объяснить тремя основными причинами: значительное снижение электронной рекомбинации; увеличение внутренней отражательной способности и увеличение поглощение света. Тем не менее существует необходимость в дальнейшем понимании механизмов потерь эффективности ФЭП. Предложена модификация стандартной производственной линии по производству ФЭП с существующей на TOO „Kazakhstan Solar Silicon“ технологии Al-BSF до PERC-технологии с использованием метода PECVD. 


\section{Конфликт интересов}

Авторы заявляют, что у них нет конфликта интересов.

\section{Список литературы}

[1] United Nations, Department of Economic and Social Affairs, Population Division (2019). World Population Prospects 2019: Highlights (ST/ESA/SER.A/423)

[2] ITRPV 2020, International Technology Roadmap for Photovoltaic. Eleventh Edition, April 2020.

https://itrpv.vdma.org/en/

[3] D. Kalygulov, I. Klinovitskaya, T. Turmagambetov, A. Pavlov, S. Plotnikov, B. Mukashev, A. Serikkanov, Z. Agabekov, D. Kantarbaeva. News National Academy Sci. Republic Kazakhstan. Physico-Mathem. Ser., 3 (325), 120 (2019). DOI: 10.32014/2019.2518-1726.18

[4] А.А. Бетекбаев, С.В. Плотников, Д.А. Калыгулов, И.А. Клиновицкая. Вестник Евраз. нац. ун-та им. Л.Н. Гумилева, 4 (119), 103 (2017).

[5] T. Dullweber, J. Schmidt. IEEE J. Photovoltaics, 6(5), 1366 (2016). DOI: 10.1109/JPHOTOV.2016.2571627

[6] A. Blakers. IEEE J. Photovoltaics, 9(3), 629 (2019). DOI: $10.1109 /$ JPHOTOV.2019.2899460

[7] M.A. Green. Solar Energy Mater. Solar Cells, 143, 190 (2015). DOI: 10.1016/j.solmat.2015.06.055

[8] A. Kumar, M. Bieri, T. Reindl, A.G. Aberle. Energy Proced., 130, 43 (2017). DOI: 10.1016/j.egypro.2017.09.412

[9] И.А. Клиновицкая, С.В. Плотников, Д.А. Калыгулов. Вестник ВКГТУ им. Д. Серикбаева, 4 (78), 67 (2017).

[10] S.L. Née Werner, M. Meßmer, S. Schmidt, E. Lohmüller, A. Piechulla, A. Wolf. In: 2018 IEEE 7 th World Conf. Photovolt. Energy Conversion, WCPEC 2018 A Jt. Conf. 45th IEEE PVSC, 28th PVSEC 34th EU PVSEC (Waikoloa, HI, USA, IEEE, 2018), p. 1530-1535. DOI: 10.1109/PVSC.2018.8547603

[11] M.Z. Rahman, S.I. Khan, Mater. Renewable Sustainable Energy, 1, 1 (2012). DOI: 10.1007/s40243-012-0001-y

[12] B. Min, M. Müller, H. Wagner, G. Fischer, R. Brendel, P.P. Altermatt, H. Neuhaus, IEEE J. Photovoltaics, 7 (6), 1541 (2017). DOI: 10.1109/JPHOTOV.2017.2749007

[13] Sh.K. Chunduri, M. Schmela. PERC Solar Cell Technology, 8, (2017).

[14] J. Schmidt, F. Werner, B. Veith, D. Zielke, S. Steingrube, P.P. Altermatt, S. Gatz, T. Dullweber, R. Brendel. Energy Proced., 15, 30 (2012). DOI: 10.1016/j.egypro.2012.02.004

[15] K. Matsunaga, T. Tanaka, T. Yamamoto, Y. Ikuhara. Phys. Rev. B. Condens. Matter Mater. Phys., 68 (8), 085110, (2003).

[16] T. Zhou, J.U. Fuchs, V.X. Nguyen, J. Rehli, A. Piechulla, S. Denzer, W. Jooss. In: 31st Eur. Photovolt. Sol. Energy Conf. Exhib, ed. by S. Rinck, N. Taylor, P. Helm (Hamburg, Germany, WIP Wirtschaft and Infrastruktur GmbH \& Co. Planungs-KG, 2015), p. 765.

DOI: 10.4229/EUPVSEC20152015-2AV.3.23

[17] H. Huang, J. Lv, Y. Bao, R. Xuan, S. Sun, S. Sneck, S. Li, C. Modanese, H. Savin, A. Wang, J. Zhao. Sol. Energy Mater. Sol. Cells, 161, 14 (2017). DOI:10.1016/j.solmat.2016.11.018

[18] T. Trupke, B. Mitchell, J.W. Weber, W. McMillan, R.A. Bardos, R. Kroeze. Energy Proced., 15, 135 (2012). DOI: 10.1016/j.egypro.2012.02.016
[19] W. McMillan, T. Trupke, J. Weber, M. Wagner, U. Mareck, Y.C. Chou, J. Wong. In: Proc. 25th EU PVSEC, Val. Spain (Valencia, Spain, WIP Renewable Energies, 2010), p. 134. DOI: $10.4229 / 25$ thEUPVSEC2010-2CO.3.5

[20] S. Johnston, F. Yan, K. Zaunbrecher, M. Al-Jassim, O. Sidelkheir, A. Blosse, In: Conf. Rec. IEEE Photovolt. Spec. Conf. (IEEE, 2011, 002885-002890), DOI: 10.1109/PVSC.2011.6186549

[21] J.-F. Leliévre, B. Kafle, P. Saint-Cast, P. Brunet, R. Magnan, E. Hernandez, S. Pouliquen, F. Massines. Progr. Photovoltaics: Research and Applications, 27 (11), 1007 (2019). DOI: 10.1002/pip.3141 